case reports

\title{
Migration of Enterprise stent in treatment of intracranial aneurysms: a report of two cases
}

\author{
Goran Pavlisa ${ }^{1}$, David Ozretic ${ }^{1}$, Marko Rados ${ }^{1}$, Gordana Pavlisa ${ }^{2}$ \\ ${ }^{1}$ Clinical Institute of Diagnostic and Interventional Radiology, University Hospital Center Zagreb, \\ Zagreb School of Medicine; ${ }^{2}$ Special Hospital for Pulmonary Diseases, Zagreb, Croatia
}

Background. We present two patients with acutely ruptured complex aneurysms of the internal carotid artery, arising at the origin of the posterior communicating artery (PComA).

Case reports. The aneurysms in both patients had a wide neck and the closed-cell stent (Enterprise) was delivered to assist in aneurysm coiling. In both patients an inadvertent migration of stent occurred, without periprocedural complications. Aneurysms were successfully embolized by endovascular coils.

Conclusions. These cases highlight the flexibility of the stent, as well as the likelihood of stent migration in the setting of immediate coiling after the placement of stent, or in adverse anatomic relations.

Key words: intracranial stent; complex aneurysm; stent migration

\section{Introduction}

In patients with large or giant intracranial aneurysms, with arterial branches originating from the aneurysm, or when wide neck of the aneurysm circumferentially involves the parent artery, the treatment is often difficult. Endovascular treatment options include the use of three-dimensional coils, stent placement, balloon remodelling ${ }^{1-3}$, the use of liquid embolics ${ }^{4}$, multiple microcatheters $^{5}$ and combinations of these approaches. $^{6-9}$ We present two patients with

Received 29 January 2009

Accepted 4 May 2009

Correspondence to: Dr. Goran Pavlisa, Clinical Institute of Diagnostic and Interventional Radiology, University Hospital Center Zagreb, Kispaticeva 12, Zagreb, Croatia. Phone: +385 1 2388118; Fax: +385 1 2388250; E-mail: gpavlisa@net.amis.hr acutely ruptured complex aneurysms of the origin of the posterior communicating artery (PComA). The patients were treated by stent-assisted coiling, using Enterprise stent, which migrated after the initial successful deployment. The stent migration occurred after a very moderate negotiation of the microcatheter through the struts of the stent in the first patient, and without any manipulation in the second patient.

\section{Case reports}

\section{Patient 1}

Clinical details

A 53-year-old female patient was admitted to hospital after suffering sudden headache accompanied with nausea, vomiting, and diplopiae. Head computerized tomography 


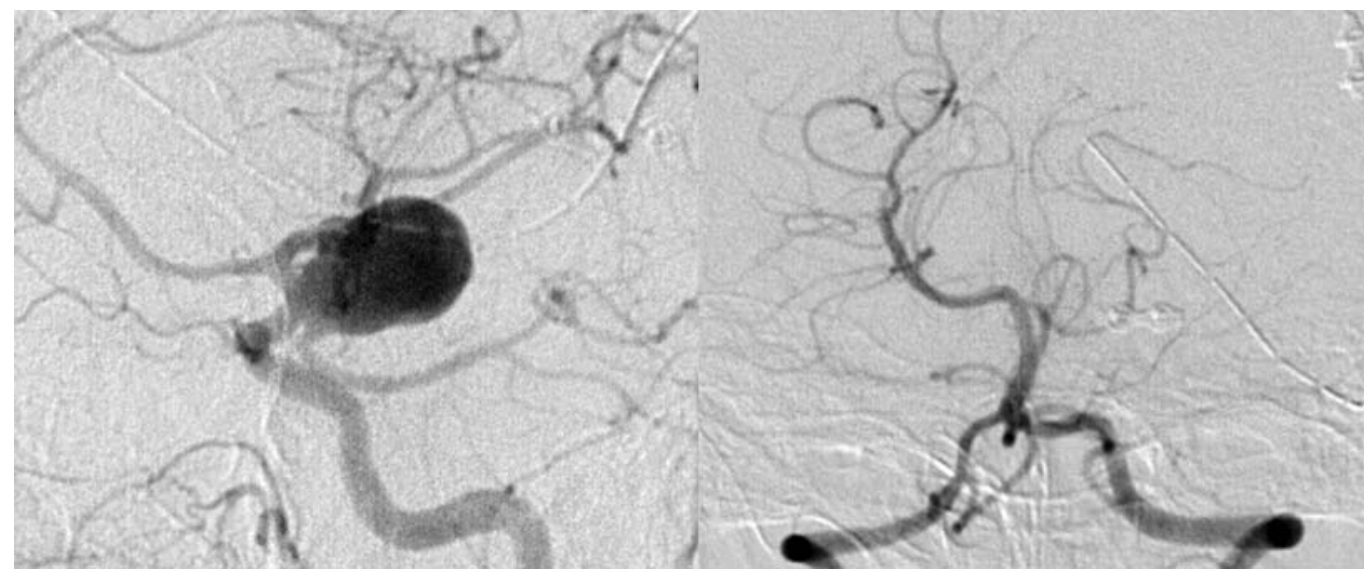

Figure 1. Large aneurysm of the posterior communicating artery origin (left). The foetal origin of the left posterior cerebral artery is shown by the left vertebral artery angiogram (right).

(CT) scan revealed diffuse subarachnoid haemorrhage (SAH) with intraventricular extension and brain oedema. CT angiography displayed a large aneurysm of the origin of posterior communicating artery (PComA), with mural thrombus and a wide neck. Left PComA was of a foetal type with the complete absence of P1 segment of the left posterior cerebral artery (PCA). The patient was referred to the open neurosurgical treatment, however, the surgical reconstruction of the neck and aneurysm occlusion could not have been performed due to a high risk of PComA occlusion and ipsilateral PCA infarction.

The patient was transferred to our institution for the endovascular treatment on the following day. The control CT showed no significant changes compared to the initial scan, with no signs of secondary ischemic changes or hydrocephalus and she underwent the immediate endovascular treatment.

\section{Endovascular treatment}

Diagnostic four-vessel angiography was performed through the right femoral approach and 6 French $(6 F)$ introducer sheath, confirming the aneurysm, with foetal left PCA. The circulating lumen of the aneurysm was large, $19 \times 13 \times 15 \mathrm{~mm}$ in diameter, with a 6 mm-wide neck (Figure 1).

A 6F guiding catheter (Multipurpose, Boston Scientific Neurovascular, Fremont, CA, USA) was placed in C1 segment of the left ICA, and the aneurysm was catheterized using Excel 0.014 inch microcatheter and Synchro 0.014 microguidewire (Boston Scientific, Fremont, CA, USA) for initial coiling with bare platinum Guglielmi detachable coils (GDCs). Eight coils were placed in the aneurysm dome, with a total length of $220 \mathrm{~cm}$. At that time, due to the risk of coil protrusion in the ICA and PComA, a microcatheter was exchanged for a Prowler select plus 21 microcatheter for the placement of closed-cell stent (Enterprise, Cordis Neurovascular Johnson \& Johnson, Miami Lakes, FL, USA). The stent, sized $4.5 \mathrm{~mm} \times 22 \mathrm{~mm}$, was placed with a proximal part in cavernous ICA and distal part in M1 segment of the left medial cerebral artery, with the intention of narrowing of the aneurysm neck. Prowler microcatheter was then exchanged for Excelsior 10 microcatheter (Boston Scientific, Fremont, CA, USA) for the purpose of aneurysm coiling. In the attempts to pass the microcatheter through the struts of the stent, due to the angle of 


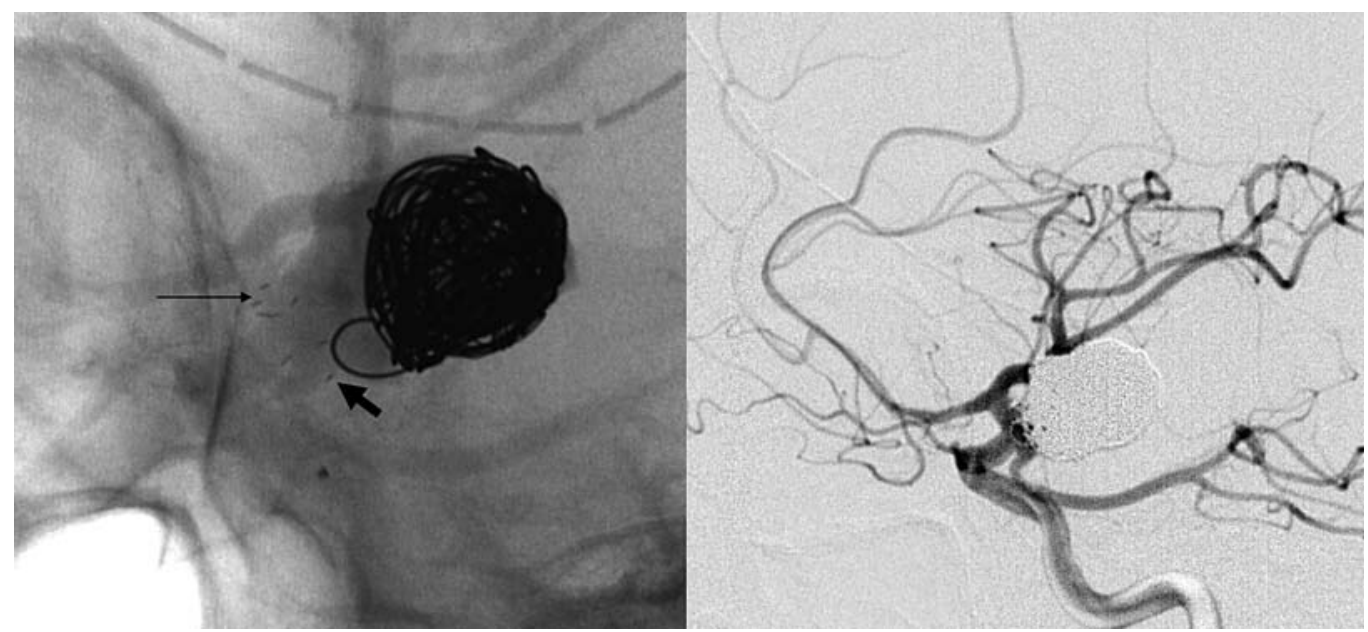

Figure 2. Radiopaque stent markers are positioned in both parts of the neck of the aneurysm, covering the neck at the internal carotid artery (thin arrow) and at the origin of posterior communicating artery (thick arrow). Near-total occlusion of the aneurysm with protrusion of one coil loop in the ICA by the side of the stent, with patent internal carotid artery and posterior communicating artery.

the ICA at the origin of the aneurysm neck, the stent was mobilised to a more proximal position, with the distal end in C7 segment of the ICA and the proximal end in the origin of PComA from the aneurysm (Figure 2). This stable position of the stent secured both ICA and PComA for the further coil embolization, with 15 GDC coils, with a total length of packed coils at the end of the procedure of $540 \mathrm{~cm}$.

During coiling, an intravenous bolus of $7 \mathrm{mg}$ of Integrilin has been administered at the time when the aneurysm was estimated to be secured from bleeding. The aneurysm was near-totally occluded, with a minimal neck remnant, and a slight coil loop protrusion in the ICA. PComA was patent with a normal flow in the left PCA at the end of the procedure.

After the procedure, a standard antiaggregation therapy was initiated, with aspirin $100 \mathrm{mg}$ daily, permanently, and clopidogrel $75 \mathrm{mg}$ daily, during 4 weeks. During the post-embolization period, the patient gradually recovered, and was discharged from the hospital to a rehabilitation centre with a moderate cognitive dysfunction.

\section{Patient 2}

\section{Clinical details}

A 54-year-old female patient was referred to the endovascular treatment of an acutely ruptured large aneurysm of PComA origin. Before the treatment, the patient was in Hunt and Hess grade II.

\section{Endovascular treatment}

At four-vessel angiography the aneurysm was irregular in shape, $14 \times 8 \mathrm{~mm}$ in diameter, with a $5 \mathrm{~mm}$-wide neck. Initial coiling attempts were unsuccessful because of a coil loop protrusion in ICA, and the Enterprise stent, $4.5 \mathrm{~mm} \times 22$ $\mathrm{mm}$, was deployed across the aneurysm neck. However, during the first control angiogram before further microcatheter manipulation, the proximal part of the stent migrated to the aneurysm neck, while the distal remained in the initial position in M1 segment of the middle cerebral artery (Figure 3). Nevertheless, this stent position enabled successful coiling, and the aneurysm was embolized with 18 coils, with a minimal neck remnant. The post-procedur- 


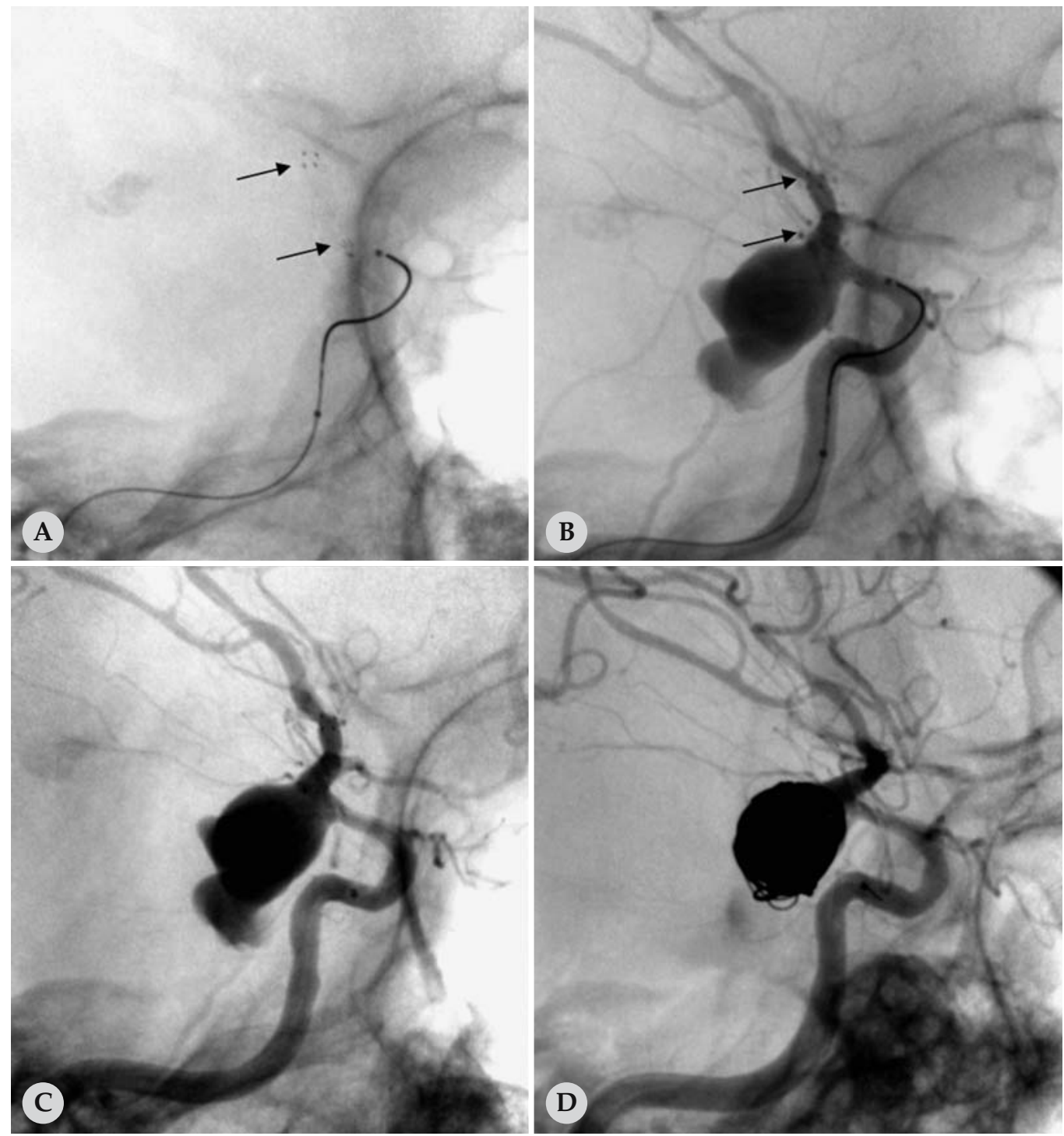

Figure 3. A: Arrows indicate proximal and distal markers of a deployed stent. B: Position of the markers after stent migration shown by arrows. Large irregular PComA aneurysm with a wide neck. C: Microcatheter in the aneurysm lumen. D: Embolized aneurysm at the end of the session.

al course was uneventful, and the patient completely recovered.

This report is written in accordance with the ethical standards laid down in the 1964 Declaration of Helsinki. Both patients gave an informed consent prior to the inclusion of the data in the report. Details that might have disclosed the iden- tity of the subject under study have been omitted.

\section{Discussion}

Self-expandable stents have increasingly been used in the treatment of various 
vascular pathology. ${ }^{10}$ The reconstruction of the parent artery at the aneurysm neck is often performed using intracranial stents, with a variety of materials, including open-cell, closed-cell stents or covered stents. ${ }^{11,12}$ Different approaches have been described, as stenting before or after coiling ${ }^{13,14}$, or in combination with balloon remodelling ${ }^{1,3,15}$, Y configuration of stents ${ }^{16}$ and stenting across the circle of Willis. ${ }^{17}$

In the first presented patient, the angle between C7 segment of the ICA and the origin of the PComA, through the neck of the aneurysm was acute, not allowing the stent to be positioned from ICA to PComA in a manner that would secure both arteries and allow the coil embolization. These patho-anatomic relations also precluded balloon remodelling. We decided to place a stent in the ICA across the aneurysm neck, thus securing the ICA and we expected that the PComA origin would be at least partly secured by the narrowed neck due to the stent. The aneurysm embolization was planned to be subtotal, to leave the origin of the PComA patent. Another option was to try to place a stent through the right ICA, via anterior communicating artery (AComA), this way placing one end of the stent in PComA, and another in left ICA. However, this option seemed complicated and not likely to succeed, due to the tortuous path through the A1 segment of the right anterior cerebral artery and AComA. The closed cell stent was initially placed in the left ICA; however, it inadvertently migrated in a much more favourable position, securing both ICA and PComA.

In the second patient, anatomic relations at the aneurysm neck were rather favourable for the stent deployment, which was technically simple. The stent migrated before any further manipulation of microcatheter, we presume because the proxi- mal part of the stent was not completely open after the microcatheter (Prowler select plus 21) withdrawal.

These cases highlight the flexibility of this stent system, without the fracture of the stent, with no angiographic or clinical signs of lesion of arterial intimal layer during the migration of the stent. There were no signs of vasospasm, dissection or thrombosis. No antiaggregation or anticoagulation therapy was administered prior to the stent placement, or even immediately after its migration, since the procedure was performed in the setting of acute $\mathrm{SAH}$, and the antiaggregation therapy was administered only after the aneurysms were mostly embolized by coils. These positions of the stents allowed for almost complete coil occlusion of the aneurysms.

The use of closed-cell intracranial stents, even in patients with large and anatomically complex aneurysms as described, seems a safe and effective treatment option. The complications are mostly related to the thrombogenicity of the stent, as well as the stent migration and malposition $^{18}$, and in-stent stenosis has also been reported. ${ }^{19}$ The timing of the stent placement in relation to coiling may be critical, since the stent migration is possible, especially in angled positions, even with a low crossing-profile of the microcatheter used to pass through the struts of the stent. The previously described variations in stent timing may indicate that it would be ideal if coiling of the aneurysm could be done before stenting, with or without the need for balloon remodelling. ${ }^{14}$ The stent placement could then be performed at the end of the procedure for the purpose of blood flow redirection and neck healing. ${ }^{6}$ However, if balloon remodelling is necessary, this makes the procedure more complicated, not without the higher risk of thrombotic complications. 
Although the open neurosurgical approach was not successful in the first patient, there is a potential for surgical techniques and dedicated materials in solving this type of problem. Parent artery sacrifice with the creation of high-flow bypass may offer the treatment to patients with aneurysms which are not accessible to endovascular techniques ${ }^{20}$, while tangential clipping and aneurysm wrapping may be used in the treatment of dissecting aneurysms ${ }^{7}$, however, such techniques are not widely available in many centres. Other endovascular techniques, such as stenting across the Circle of Willis ${ }^{17}$, balloon neck remodelling ${ }^{2}$ or catheter-assisted GDC embolisation ${ }^{21,22}$ may also be used in the treatment of complex aneurysms, depending on the tortuousity of path through the Circle of Willis, or the possibility of adequate positioning of the balloon or assisting microcatheter.

\section{References}

1. Aletich VA, Debrun GM, Misra M, Charbel F, Ausman JI. The remodelling technique of balloon-assisted Guglielmi detachable coil placement in wide-necked aneurysms: experience at the University of Illinois at Chicago. J Neurosurg 2000; 93: $388-96$

2. Fiorella D, Albuquerque FC, Masaryk TJ, Rasmussen PA, McDougall CG. Balloon-in-stent technique for the constructive endovascular treatment of "ultra-wide necked" circumferential aneurysms. Neurosurgery 2005; 57: 1218-27.

3. Moret J, Cognard C, Weill A, Castaings L, Rey A. Reconstruction technic in the treatment of wideneck intracranial aneurysms. Long-term angiographic and clinical results. Apropos of 56 cases. J Neuroradiol 1997; 24: 30-44.

4. Molyneux AJ, Cekirge S, Saatci I, Gal G. Cerebral Aneurysm Multicenter European Onyx (CAMEO) trial: results of a prospective observational study in 20 European centers. AJNR Am J Neuroradiol 2004; 25: 39-51.
5. Kwon OK, Kim SH, Oh CW, Han MH, Kang HS, Kwon BJ, et al. Embolization of wide-necked aneurysms with using three or more microcatheters. Acta Neurochir (Wien) 2006; 148: 1139-45.

6. Szikora I, Berentei Z, Kulcsar Z, Barath K, Berez A, Bose A, et al. Endovascular treatment of intracranial aneurysms with parent vessel reconstruction using balloon and self expandable stents. Acta Neurochir (Wien) 2006; 148: 711-23.

7. Uhl E, Schmid-Elsaesser R, Steiger HJ. Ruptured intracranial dissecting aneurysms: management considerations with a focus on surgical and endovascular techniques to preserve arterial continuity. Acta Neurochir (Wien) 2003; 145: 1073-84.

8. Wehman JC, Hanel RA, Levy EI, Hopkins LN. Giant cerebral aneurysms: endovascular challenges. Neurosurgery 2006; 59: 125-38.

9. Wells-Roth D, Biondi A, Janardhan V, Chapple K, Gobin YP, Riina HA. Endovascular procedures for treating wide-necked aneurysms. Neurosurg Focus 2005; 18: e7.

10. Gjikoli B, Hadzihasanovic B, Jaganjac S, Herceglija E, Niksic M, Hadzimehmedagic A, et al. Treatment of complicated case with subclavia steal syndrome and stenosis of common iliac artery. Radiol Oncol 2008; 42: 1-12.

11. Akpek S, Arat A, Morsi H, Klucznick RP, Strother CM, Mawad ME. Self-expandable stent-assisted coiling of wide-necked intracranial aneurysms: a single-center experience. AJNR Am J Neuroradiol 2005; 26: 1223-31.

12. Saatci I, Cekirge SH, Ozturk HM, Arat A, Ergungor F, Sekerci Z, et al. Treatment of internal carotid artery aneurysms with a covered stent: experience in 24 patients with mid-term follow-up results. AJNR Am J Neuroradiol 2004; 25: 1742-9.

13. Benitez RP, Silva MT, Klem J, Veznedaroglu E, Rosenwasser RH. Endovascular occlusion of wide-necked aneurysms with a new intracranial microstent (Neuroform) and detachable coils. Neurosurgery 2004; 54: 1359-68.

14. Biondi A, Janardhan V, Katz JM, Salvaggio K, Riina HA, Gobin YP. Neuroform stent-assisted coil embolization of wide-neck intracranial aneurysms: strategies in stent deployment and midterm follow-up. Neurosurgery 2007; 61: 460-8.

15. Cekirge SH, Yavuz K, Geyik S, Saatci I. HyperForm balloon-assisted endovascular neck bypass technique to perform balloon or stent-assisted treatment of cerebral aneurysms. AJNR Am J Neuroradiol 2007; 28: 1388-90 
16. Chow MM, Woo HH, Masaryk TJ, Rasmussen PA. A novel endovascular treatment of a wide-necked basilar apex aneurysm by using a Y-configuration, double-stent technique. AJNR Am J Neuroradiol 2004; 25: 509-12.

17. Kelly ME, Turner R, Gonugunta V, Woo HH, Rasmussen PA, Masaryk TJ, et al. Stent reconstruction of wide-necked aneurysms across the circle of Willis. Neurosurgery 2007; 61: 249-54.

18. Yahia AM, Gordon V, Whapham J, Malek A, Steel J, Fessler RD. Complications of Neuroform stent in endovascular treatment of intracranial aneurysms. Neurocrit Care 2008; 8: 19-30.

19. Fiorella D, Albuquerque FC, Deshmukh VR, McDougall CG. In-stent stenosis as a delayed complication of Neuroform stent-supported coil embolization of an incidental carotid terminus aneurysm. AJNR Am J Neuroradiol 2004; 25: 1764-7.

20. Streefkerk HJN, Wolfs JFC, Sorteberg W, Sorteberg AG, Tulleken CAF. The ELANA technique: constructing a high flow bypass using a non-occlusive anastomosis on the ICA and a conventional anastomosis on the SCA in the treatment of a fusiform giant basilar trunk aneurysm. Acta Neurochir (Wien) 2004; 146: 1009-19.

21. Ihn YK, Kim DI, Kim BS, Lee JM. Utility of catheter-assisted Guglielmi detachable coiling in the treatment of wide-necked aneurysms. Acta Neurochir (Wien) 2006; 148: 1045-52.

22. Vanninen R, Manninen H, Ronkainen A. Broadbased intracranial aneurysms: thrombosis induced by stent placement. AJNR Am J Neuroradiol 2003; 24: $263-6$. 